\title{
Uso de las aplicaciones del Smartphone en el fotoperiodismo
}

\section{Use of smartphone applications in photojournalism}

\author{
Yulvitz Ramón Quiroz Pacheco* \\ Escuela Profesional de Ciencias de la Comunicación, \\ Universidad de San Martín de Porres, Perú
}

\section{Resumen}

Las nuevas tecnologías de la información y comunicación (NTIC) tienen incidencia directa en el quehacer y desarrollo del ser humano, por ello, es necesario que toda persona conozca el uso correcto de estas herramientas para desenvolverse mejor en su vida cotidiana, tanto en el ámbito personal como también profesional.

Precisamente, el objetivo del presente estudio es mostrar cómo uno de los principales instrumentos de las NTIC, el Smartphone, es empleado por el fotoperiodista para realizar y mejorar su labor profesional, considerando que el teléfono inteligente cuenta con diversas aplicaciones (apps) para optimizar la captación de una buena imagen fotoperiodística.

Gracias a la variedad de apps que el Smartphone proporciona, el fotoperiodista puede equilibrar y ajustar -previo a la realización de su labor profesional- cantidad de luz, balance, combinar modos de disparo, tiempo, distancia de enfoque y otros detalles, para así, tener la posibilidad de brindar una imagen de calidad acorde al fotoperiodismo en este contexto digital.

Palabras clave: nuevas tecnologías de la información y comunicación, fotoperiodismo, Smartphone, aplicaciones, periodismo digital.

Este es un artículo Open Access bajo la licencia Creative Commons Atribución-NoComercial-Compartirlgual 4.0

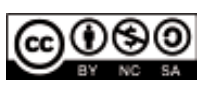




\begin{abstract}
It is currently known that the new technologies of information and communication (NTICs) directly affect the tasks and development of human beings. In this sense, it is necessary that everyone knows the correct use of those tools to better perform in their daily lives, both in personal and professional areas.
\end{abstract}

The objective of this study is to show how one of the main tools of the NTICs, the smartphone, is used by photojournalists to do and improve their professional work, considering that smartphones have several applications (apps) to optimize the capture of a good photojournalistic image.

Using the different apps provided by the smartphone, photojournalists are able to balance and set the device before performing their professional work: amount of light, balance, combination of shooting modes, time, focusing distance, among other details. In this way, they offer a quality image in keeping with digital photojournalism.

Keywords: new technologies of the information and communication, photojournalism, smartphone, applications, digital journalism.

\title{
Introducción
}

En el contexto tecnológico que las personas llaman sociedad de la información, es necesario que el profesional en fotoperiodismo se capacite continuamente en el uso de herramientas tecnológicas del siglo XXI, entre ellas, el Smartphone, puesto que este valioso recurso le proporciona diversas aplicaciones que le servirán para captar imágenes de calidad en beneficio de su ejercicio profesional.

En ese sentido, este estudio dará a conocer únicamente las apps que el fotoperiodista puede emplear previamente a la realización de su labor profesional, y no aquellas aplicaciones que pueden utilizarse de manera posterior a dicho trabajo, como las destinadas a la edición fotográfica, ya que a esto lo consideramos como manipulación periodística. 


\section{El fotoperiodismo en la era digital}

En la prensa escrita la fotografía tiene un fin en sí: ser un complemento que ilustra el hecho motivo de la información. Desde esa perspectiva, la fotografía es una forma de lenguaje que transmite un mensaje el cual narra la cotidianidad de la sociedad; además de ser un elemento de expresión artística que posee un rol fundamental en la consolidación de la memoria colectiva de un pueblo.

Y es así que la fotografía como elemento de expresión nos ofrece una visión codificada e interpretativa de un contexto determinado, otorgando permanencia a lo transitorio y efímero, y proporcionando un estudio semiótico a la significación de su mensaje. En esa perspectiva, el reconocido promotor de arte español especializado en fotografía, Jean Fontcuberta, refiere:

Hace años ya enviábamos postales: una combinación de fotografía y texto que componía un mensaje. Hoy no cesamos de repetir ese gesto con los emails, whatsapps y todo tipo de mensajes electrónicos. Lo hacemos con tanta profusión que al final hemos adoptado la fotografía como una forma de lenguaje con el que nos expresamos corrientemente. Antes, la fotografía era escritura; hoy es, sobre todo, lenguaje. (como se citó en Espejo, 2015, párr. 6)

Pero antes de hablar de fotoperiodismo, debemos indicar qué es exactamente una información periodística. Para Mc Bride (1980), la información puede verse como un producto de la comunicación, esto es, «las noticias, los datos, y varios otros contenidos y productos de los medios masivos, las actividades o las industrias culturales» (p. 258). Con ello podemos indicar que el término de información se enfoca en aquellos signos y mensajes codificados que serán transmitidos en un proceso más integral: la comunicación, la cual se instaura en un intercambio de mensajes dentro del contexto sociológico del actuar humano.

Siendo así alcanzamos definir a la información periodística como un contenido que busca dar a conocer y entender un acontecimiento novedoso, por medio de un proceso de selección, interpretación y tratamiento de las realidades cotidianas, cuyo conocimiento se considera de interés para una 
colectividad y que es difundido, en un proceso comunicativo, por medio de los medios masivos de comunicación, con la finalidad de otorgar un saber objetivo, crítico y ético a la sociedad para la generación de ciudadanía.

Basamos esta apreciación en la definición que realiza Galdón (2001) sobre este concepto, puesto que para él la información periodística es «un saber sobre las realidades humanas actuales con proyección e interés social, compartido por periodistas y ciudadanos, mediante el diálogo sobre los textos elaborados por aquéllos y difundidos por los medios de comunicación» (p. 47).

Ahora bien, llevando estas nociones al ámbito del fotoperiodismo consideramos que aquel es la captura icónica de un acontecimiento real, el cual es interpretado visualmente con un criterio periodístico por un fotoperiodista, y cuyo mensaje visual será descifrado por el público receptor según su competencia icónica y conocimiento de su realidad. Referimos ello basándonos en la definición dada por Caballo (1994), quien sostiene que «la fotografía de prensa, el fotoperiodismo, es la captura de noticias, la obtención de fragmentos de realidad que tiene que decir, a veces con un solo fotograma, qué ha pasado. Esa foto ha de ser síntesis del acontecimiento» (p. 278).

Agregamos, que la imagen fotoperiodística no solo interpreta la realidad como también lo realizan otras formas de representación visual (como la pintura o el dibujo, por ejemplo), sino que adicionalmente proporciona una fuerte sensación de representación verídica de la realidad. Ello debido a que la sociedad siempre ha considerado más creíble lo captado o diseñado por un instrumento tecnológico (una cámara fotográfica o un Smartphone) en comparación a lo elaborado por la mano del ser humano (un bosquejo o croquis).

Y es esa idea de que una fotografía refleja al 100\% una realidad, el motivo por el cual a la imagen fotoperiodística se le confiere una credibilidad informativa superior que a las otras formas de representación visual anteriormente indicadas. Ello debido a que la invención de la fotografía y su posterior evolución han «modificado profundamente las relaciones que mantiene el hombre con el mundo de los signos, por tanto con la realidad. La grabación química o física de señales visibles, inmóviles o móviles, se identifican cada día más con la información como tal» (Schaeffer, 1990, p. 7). 
Pero, ¿cómo es que el contexto digital ha favorecido el desarrollo de la fotografía? En un primer punto podemos señalar la eliminación del proceso de revelado que en muchos casos puso en peligro, o incluso estropeó, el trabajo del fotoperiodista. El caso más recordado al respecto es el acontecido con el trabajo de Robert Capa luego de capturar con su lente el desembarco de las tropas aliadas en la playa Omaha en Normandía.

Tras haber realizado su trabajo en el norte de Francia, Capa mandó sus carretes a la redacción de la revista Life en el Reino Unido. Ahí, por el nerviosismo del momento y con la prisa y presión de publicar las primeras fotografías de aquel hito histórico conocido como el Día D, el técnico de laboratorio se equivocó al cerrar las puertas del armario donde se estaban secando los negativos y la emulsión se malogró. De las 106 fotografías enviadas por Capa, solo 11 lograron salvarse y de ellas ocho fueron publicadas.

Sobre aquel suceso, el editor de fotografía de Life durante la Segunda Guerra Mundial, John G. Morris (como se citó en Altares, 2014, párr. 4), escribió en sus memorias que gracias al coraje de Robert Capa y la buena suerte que tuvieron en la oficina de revelado en Londres, «unas pocas fotografías del Día D ocupan un lugar en la historia visual de nuestro siglo. Sin embargo, siempre me perseguirá el fantasma de lo que perdimos».

Otro ámbito que ha sido anulado casi totalmente es la limitación de fotografías que proporcionaba el carrete, puesto que en la actualidad las tarjetas de memoria que se usan en los equipos fotográficos o los Smartphone pueden almacenar miles de imágenes. Y es que anteriormente, al contar solo con la cámara analógica, y de no ser por la pericia y sentido de la reserva del fotoperiodista, posiblemente muchos íconos históricos hubieran pasado desapercibidos y no existirían en la memoria de la humanidad.

Una imagen que ejemplifica claramente esta situación, fue la obtenida por el fotógrafo de la agencia Associated Press, Nick Ut, en junio de 1972 durante la guerra de Vietnam. En aquella ocasión, gracias a una cuarta cámara fotográfica que siempre tenía como reserva, el fotoperiodista vietnamita logró captar el llanto desesperado de una niña de nueve años, Kim Phuc, cuyo cuerpo estaba siendo quemado por el napalm que había sido lanzado por un avión de Vietnam del Sur. 
Aquel día los fotoperiodistas que cubrían el acontecimiento captaron otras imágenes, entre ellas la de una señora que cargaba a su bebé y escapaba del bombardeo. Al acabárseles la capacidad de sus carretes fotográficos se retiraron del lugar, y esa fue la razón por la que Nick Ut, con su cuarta cámara de reserva, fuera el único fotoperiodista que lograra captar el momento en el que Kim Phuc huía del bombardeo. "Cuando pasó la señora mayor con el bebé, todos los fotógrafos tomaron muchísimas fotos y las cámaras hace treinta años no eran como las de ahora. Cuando Kim apareció corriendo, muchos fotógrafos estaban rebobinando el rollo», refirió Nick Ut en una conversación con Martins (2006, párr. 8).

Adicionalmente a las situaciones mencionadas, una última es la mejora en la transmisión del trabajo fotoperiodístico, puesto que Internet permite que se realice inmediatamente a través de diversos medios: página web, redes sociales, blogs, etc., con lo cual incluso se puede llegar al usuario de manera directa.

Asimismo, la variedad de aplicaciones y elementos que hoy abundan en la red de redes permiten que las imágenes puedan ser observadas con mayor interactividad. Así por ejemplo, se puede realizar el reconocimiento facial o etiquetar a alguien reconocido en la fotografía, $u$ obtener información adicional abriendo una pestaña a modo de leyenda. Al respecto, en un diálogo con Monje (2017), la fotógrafa con estudios en antropología, Paula Cisterna, manifiesta que «hoy en día el mejor formato es sin duda internet, porque te da una posibilidad única para mostrar tu trabajo. De esta forma puedes acceder a fotos de forma cotidiana y de manera más simple» (párr. 1).

Tal como observamos, el contexto digital ha favorecido en mucho el desarrollo del fotoperiodismo. De haber tenido una cámara digital o Smartphone al momento de captar las imágenes con las que marcaron un hito histórico en la fotografía y para la humanidad, a Capa no se le hubieran estropeado sus 106 fotografías puesto que hoy él hubiera podido captar las imágenes y enviarlas casi en simultáneo a sus redes sociales o drive, y así tenerlas almacenadas de manera segura en 'la nube' para luego transmitirlas a su editor en Londres; y Nick Ut no hubiera tenido la necesidad de tener y cargar tantos equipos fotográficos ya que la memoria de una solo cámara digital o Smartphone puede albergar miles de imágenes, siendo ventajas adicionales del teléfono inteligente su peso liviano y pequeño tamaño. 
Sin embargo, este contexto digital también ha generado que en la actualidad se presenten situaciones negativas para el ámbito laboral del fotoperiodismo. Así, en el último estudio realizado por World Press Photo ${ }^{1}$ (2016), The state of news photography 2016, en conjunto con la University of Stirling, se resalta lo siguiente:

- De los 1991 fotoperiodistas encuestados de más de 100 países, el 54\% trabaja por su propia cuenta (freelance). Por lo tanto, la cifra desciende notablemente del $74 \%$ en 2015 al $61 \%$ en 2016, respecto a quienes laboran a tiempo completo.

- Una proporción menor de encuestados informó haber obtenido todos sus ingresos de la fotografía, del 43\% en el 2015 al 39\% en 2016, reforzando el argumento de que los fotoperiodistas diversifican sus ingresos y dependen menos de la fotografía.

- Casi dos tercios de los fotógrafos (63\%) refirió haber trabajado como intermediario: el $24 \%$ señaló que era su forma de trabajo principal, y el $39 \%$ indicó haber laborado de esta manera solo de vez en cuando. Entiéndase como intermediario al fotoperiodista que no forma parte del personal de una organización, pero que contribuye con su trabajo para aquella institución.

- El 91\% dice enfrentar riesgos físicos al ejercer su labor profesional, a la vez que solo el $13 \%$ manifestó haber obtenido ingresos por regalías de sus fotografías.

Tal como se aprecia en estas cifras, el trabajo del fotoperiodista en este contexto digital se ha convertido en una ardua labor que lamentablemente está conllevando a que muchos profesionales opten por convertirse en freelance y decidan dedicarse a otras actividades antes que a la propia tarea fotoperiodística.

Uno de los casos más alarmantes al respecto sucedió en 2013 cuando el diario estadounidense Chicago Sun-Times anunció el despido de todo su

World Press Photo es una organización sin fines de lucro que organiza el más prestigioso concurso anual de fotografía de prensa. Tiene como misión organizacional mostrar historias visuales de alta calidad que motiven a la gente a detenerse, sentir, pensar y actuar, alentando las diferentes perspectivas de la sociedad. 
personal fotoperiodístico, 28 en total, entre quienes destacaba el ganador del Premio Pulitzer, John White. Sobre ello, el diario justificó su decisión señalando que aquello era parte de una reestructuración de su personal multimedia ya que el negocio de los medios de comunicación estaba cambiando aceleradamente y que las audiencias buscaban más contenido de video con sus noticias.

Adicionalmente, otro aspecto que en la actualidad hace notar la precariedad del trabajo fotoperiodístico, y del periodismo en general, radica en el alto porcentaje de profesionales freelance que existe. El Informe anual de la profesión periodística 2017 de la Asociación de la Prensa de Madrid - APM (2017) resalta que en España, Reino Unido, Francia e Italia, el porcentaje de profesionales del periodismo, entre ellos los fotoperiodistas, en situación de freelance o autónomos es de $49.4 \%, 35 \%, 25 \%$ y $65 \%$, respectivamente.

Ante esta situación, en una carta abierta publicada en su edición web, el Colegio de Periodistas de Cataluña (2018), sostiene:

La firma del fotógrafo debe ser garantía de profesionalidad y veracidad. En cambio, las secciones de Fotografía cada vez tienen menos poder de decisión. Prueba de ello es la casi desaparición de los editores gráficos -básicos para filtrar en la sobreabundancia de imágenes y mantener la calidad-, la precariedad crónica y los constantes despidos de profesionales, sustituidos por imágenes de procedencia dudosa (por no decir malintencionada). (párr. 4)

Pese a esta situación, la investigación de World Press Photo mencionada anteriormente, destaca que el $60 \%$ de los fotoperiodistas indican estar muy feliz con su combinación actual de tareas, pues consideran que la fotografía es una actividad agradable y hoy existen más oportunidades que antes para contar historias visualmente.

Teniendo esta perspectiva cabe preguntarse entonces cuál es el perfil que debe tener un fotoperiodista. $\mathrm{Al}$ respecto muchos autores han señalado las diversas características y comportamientos profesionales que deben guiar el camino de toda persona que se dedica a esta labor. Sin embargo, una breve encuesta realizada por Castellanos (2004) entre expertos y profesionales del 
fotoperiodismo ${ }^{2}$, resaltó que la característica principal que debe poseer un fotoperiodista es la capacidad crítica y cultura general.

Con esa noción logramos apreciar la importancia que la labor del fotoperiodista tiene para el ejercicio del periodismo. El ser un profesional de la fotografía no equivale únicamente al simple hecho de agarrar una cámara fotográfica, salir a la calle y captar una imagen que posteriormente se verá bonita cuando sea publicada. En eso no consiste su trabajo. La real labor de un profesional del fotoperiodismo es comprender y analizar el contexto que está observando para luego transmitir por medio de sus fotografías un mensaje no verbal que promueva una reflexión en el receptor, otorgándole una perspectiva real de los acontecimientos que le rodean. En ese sentido, el fotoperiodista debe desarrollar con sus imágenes un discurso visual narrativo y crítico de la realidad; tal como lo resaltó en una entrevista con Sanmoran (2017) la fotoperiodista Anna Surinyach:

Creo que algo importante cuando llegas a un sitio es entender lo que está pasando, si tú no entiendes lo que está pasando difícilmente vas a poder contarlo o explicarlo (...) Ya no basta con ser el primero en llegar a un sitio, es más, seguramente ya habrá llegado alguien a ese sitio antes que tú, lo que tiene que tener el fotógrafo es desarrollar un discurso visual; yo creo que el fotoperiodismo tiene que ir en esa línea. (párr. 14 y 25)

Pero además de esta característica primordial, consideramos que un fotoperiodista también debe contar con otras cualidades para el desarrollo de su labor, siendo las principales:

- Ética, compromiso social y sensibilidad humana.

- Criterio para decidir si una imagen tendrá interés periodístico o no.

2 Los fotoperiodistas partícipes en este cuestionario fueron Marco Antonio Cruz (coordinador del departamento de fotografía de la revista Proceso - México), Luis Jorge Gallegos (autor del libro Autorretratos del fotoperiodismo mexicano. 23 testimonios), Francisco Mata (ganador de innumerables premios, es uno de los exponentes más reconocidos de la fotografía contemporánea), Ernesto Ramírez (miembro del Sistema Nacional de Creadores de Arte - México), Enrique Villaseñor (investigador en periodismo, fotografía y técnicas multimedia), y el propio Ulises Castellanos (columnista y editor de fotografía en el diario El Universal - México). 
- Conocimiento y creatividad para aplicar las técnicas fotográficas.

- Capacidad de respuesta para afrontar distintas situaciones.

- Capacitación continua para conocer los cambios tecnológicos vinculados a su profesión, y así estar actualizado en software de imagen y tecnología digital.

Y es justamente este último punto por el cual un fotoperiodista debe hallarse en continuo estudio, puesto que los nuevos elementos tecnológicos, como el Smartphone, permiten que un profesional del fotoperiodismo tenga un mejor desenvolvimiento en su labor obteniendo imágenes de mayor calidad que superan incluso a las logradas por cámaras digitales.

\section{El Smartphone como herramienta del fotoperiodismo}

Como hemos mencionado al inicio de este texto, el ser humano cuenta con diversos elementos tecnológicos que la sociedad digital actual ha puesto a su disposición, tanto en su vida personal como también profesional.

En este último aspecto, el fotoperiodista ha tenido que ir adaptando el empleo de los distintos y diversos equipos tecnológicos a su labor profesional, entre ellos el Smartphone, el cual es un dispositivo móvil que puede trabajar a la misma velocidad que una minicomputadora gracias a su mayor conectividad a Internet y amplia capacidad para almacenar información comparándolo con un teléfono móvil convencional, lo cual le permite realizar distintas actividades siendo una de aquellas la captación de imágenes.

Respecto a cómo se aprecia actualmente el avance de la tecnología en este ámbito, tenemos que el estudio realizado por Telefónica (2017), Sociedad Digital en España 2017, destaca que a finales de aquel año se llegó a los 4300 millones de suscripciones de banda ancha móvil, siendo un total de 56.4 usuarios por cada 100 habitantes, situando a este instrumento tecnológico como un eje esencial para acceder a Internet. De igual manera, este informe resalta que en 2016 el $60 \%$ de la población mundial ya tenía acceso a redes 4G, teniendo una penetración de $93 \%$ en los países desarrollados y del $50 \%$ en las naciones en vías de desarrollo, estimando que en estos últimos se alcance el $70 \%$ para el año 2020 . 
Sin embargo, en agosto de este año se presentó en Chicago el primer Smartphone con la capacidad para conectarse a la red 5G, el Motorola Moto Z3, el cual recién entrará al mercado en 2019 en algunas ciudades de Estados Unidos, llegando a las principales urbes del mundo en el 2020. Sobre ello, el informe Ericsson Mobility Report, de Ericsson (2018), sostiene que para fines de 2023 se proyectan más de mil millones de suscripciones para banda ancha móvil mejorada 5G, lo cual representa el $12 \%$ de todas las suscripciones a dispositivos móviles.

Continuando con lo trazado por Telefónica se tiene que la penetración de telefonía móvil a nivel mundial logró en 2017 las 103.5 líneas por cada 100 habitantes, representando ello un total de 7740 millones de suscripciones; y en lo referente a Internet, esta herramienta tecnológica tuvo una penetración que llegó a los 3578 millones de usuarios a nivel mundial. Además de ello, el tráfico móvil tendrá una tasa compuesta de crecimiento anual del $46 \%$ entre el 2016 y 2021.

De igual manera una investigación del Groupe Speciale Mobile Association - GSMA (2018), The Mobile Economy 2018, afirma que durante el año 2017 el Smartphone alcanzó los cinco mil millones de suscriptores únicos, resaltando que esa cifra llegará a los 5900 millones en el año 2025, lo que equivaldrá al $71 \%$ de la población mundial.

Ahora bien, ¿cuáles son los mejores Smartphone que podemos emplear en el ejercicio profesional del fotoperiodismo? Al respecto, un estudio realizado por DxOMark ${ }^{3}$ (2017) señala que los mejores teléfonos inteligentes para captar fotografías son: Samsung Galaxy Note 8 (94 puntos), Apple iPhone 8 Plus (94 puntos), Apple iPhone X (97 puntos), Huawei Mate 10 Pro (97 puntos) y Google Pixel 2 (98 puntos).

Los puntajes y clasificaciones de DxOMark (2017) se basan en probar cada cámara usando un proceso idéntico y extenso que incluye obtener 1500 imágenes, las cuales se captan en situaciones de laboratorio y del mundo real

Propiedad de DxO Labs (empresa francesa dedicada a la fotografía), DxOMark es un punto de referencia independiente que evalúa científicamente la calidad de imagen de los teléfonos inteligentes, lentes y cámaras. 
utilizando una amplia variedad de temas. Con esa información, pasaremos a explicar las características que posee la cámara fotográfica de cada uno de estos equipos móviles para el ejercicio del fotoperiodismo.

- Samsung Galaxy Note 8: Cuenta con una doble cámara ISOCELL de 12 megapíxeles con aperturas focales de 1.7 (con tecnología Dual Pixel) y 2.4 (con autoenfoque), ambas a color y con estabilización de imagen óptica (OIS), para cuando la cámara esté en movimiento. Tiene la opción ‘Live focus' con el que se genera un desenfoque de fondo (efecto bokeh), además de la captura doble que permite fotografiar al mismo tiempo lo que estamos encuadrando así como lo que acontece fuera del marco. Además, su cámara con ángulo amplio logra capturar más luz con sus grandes píxeles de $1.4 \mu \mathrm{m}$, bajando así el nivel de ruido en la imagen (granos que aparecen en las fotografías al ser captadas en entornos oscuros).

- Apple iPhone 8 Plus: Posee dos sensores de 12 megapíxeles, un gran angular (lente de seis elementos de f/1.8 y con OIS) y un teleobjetivo (lente con apertura $\mathrm{f} / 2.8$ ). La acción conjunta de ambos sensores permite el zoom óptico $2 x$ y el modo retrato. Tiene además un sistema de inteligencia artificial que realiza una evaluación más precisa del rostro y de su iluminación, lo cual brinda diversos efectos en la imagen. Cuenta también con zoom digital de hasta 10x, un procesado en tiempo real más potente gracias al chip 'A11 Bionic' con el que se alcanza un 70\% de rendimiento y eficiencia energética, el Flash Quad-LED True Tone con sincronización lenta que permite utilizar la luz natural del ambiente para alcanzar un efecto más original, autoenfoque con 'Focus Pixels' y captura de imagen en formatos HEIF y JPEG.

- Apple iPhone X: Tiene dos sensores de 12 megapíxeles (ambas con OIS y más rápidos que sus predecesores), un gran angular (lente con apertura f/ 1.8) y un teleobjetivo (lente con apertura $\mathrm{f} / 2.4$, con el que se logran captar mejores imágenes en entornos oscuros con menor ruido). Cuenta asimismo con la nueva funcionalidad 'Iluminación de Retrato', que posee detección de profundidad y mapeo facial preciso, el cual permite desarrollar efectos de iluminación con calidad de estudio. Tiene un zoom óptico $2 x$ y un zoom digital de hasta 10x, un flash de 4 LEDs para resolver con mayor eficacia los ambientes de baja luminosidad, el microprocesador 'A11 Bionic' que 
produce hasta 600 mil millones de operaciones por segundo gracias a sus dos núcleos de alto rendimiento, pixeles más profundos y el HDR automático para fotos con el que se comprende el mayor nivel posible de niveles de exposición en todos los ámbitos de la imagen.

- Huawei Mate 10 Pro: Cuenta con una doble cámara Leica con lentes SUMMILUX-H, ambos con apertura focal de 1.6. El sensor monocromo de 20 megapíxeles con Flash LED Dual y el sensor RGB de 12 megapíxeles con OIS, capturan más luz permitiendo desarrollar diversos efectos en la imagen: desenfoque de fondo, HDR, modo retrato, fotografía nocturna, blanco y negro, zoom híbrido, etc., además de lograr una escasa presencia de ruido en fotografías de poca luminosidad. Asimismo, al tener en su sistema los algoritmos fotográficos inteligentes propios de la tecnología de Inteligencia Artificial (IA), la configuración de la cámara identifica en tiempo real diversos tipos de escena $u$ objeto (alimentos, mascotas, ambientes, nocturnas, etc.), ajustando de manera automática el color, contraste, brillo y exposición.

- Google Pixel 2: El poseer un solo sensor de 12.2 megapíxeles y un lente con apertura focal 1.8, además de lograr el efecto bokeh con una calidad idéntica a la de los Smartphone que cuentan con dos lentes, le ha permitido a la segunda generación móvil de Google ocupar el primer puesto de este estudio. Su originalidad radica en aprovechar la fotografía computacional: al captar un ambiente u objeto, la cámara registrará varias imágenes cuyos píxeles serán analizados y combinados de manera automática e instantánea con los algoritmos fotográficos inteligentes acordes a la tecnología de Inteligencia Artificial especialmente diseñados para esa función, obteniendo con ello la mejor calidad de una fotografía. Otro aspecto a destacar es su balance de blancos, con el que se pueden conseguir imágenes de gran nitidez con colores naturales, no importando si son realizados en ambientes externos o internos. Otras características de la cámara de este Smartphone son el enfoque automático con láser, la detección de fase dual de píxeles, la estabilización de imagen óptica y píxeles de $1.4 \mu \mathrm{m}$ que permiten bajar el nivel de ruido en la imagen.

Tal como observamos el fotoperiodista tiene a su disposición diversos Smartphone que le proporcionan una extensa variedad de recursos para 
desarrollar de manera idónea su labor profesional, además de poder acceder a Internet y a su archivo de imágenes en cualquier momento; y lo mejor de aquello, realizar toda esta labor con un elemento tecnológico cuyo peso no supera los 150 gramos y que puede ser llevado tranquilamente en alguno de sus bolsillos, ya sea de camisa o pantalón.

Un hecho que marcó un hito en el fotoperiodismo profesional ocurrió en el 2011 cuando se constituyó el ‘Grupo de Fotografía con el móvil' o 'Mobile Photo Group' (MPG), un colectivo internacional que aunaba a fotógrafos de distintas disciplinas con la finalidad de instituir un estándar de calidad para la fotografía móvil. De igual modo, un año antes, en el 2010, el fotoperiodista del The New York Times, Damon Winter, realizó una serie fotográfica haciendo uso de la app Hipstamatic de su iPhone 4; con dicho trabajo, ganó el premio 'Mejor fotógrafo de periódico' del Pictures of the Year ${ }^{4}$ de aquel año.

Tras convivir casi una semana con las tropas del Primer Batallón de la Décima División de Montaña en Nahr-i-Sufi (Afganistán), Winter logró instantáneas de gran naturalidad, al darse cuenta que la cámara de su móvil pasaba prácticamente desapercibida entre los soldados, lo cual le permitió integrarse más con ellos y así obtener una mayor espontaneidad de su parte, situación que desaparecía cuando sacaba su cámara fotográfica con lente gran angular. En un artículo escrito para The New York Times, Through My Eye, Not Hipstamatic's, Winter (2011) refiere que el uso del Smartphone es discreto y no intimida, con lo cual se consiguen registrar imágenes instantáneas más interesantes. Añadió que el teléfono móvil le permitió abordar los temas de manera diferente y que su uso le hizo observar detalles que de otra manera habría perdido.

Otro acontecimiento retratado por un Smartphone fue los Juegos Olímpicos de Londres 2012. En aquella ocasión el fotoperiodista Dan Chung fotografió las diversas competencias deportivas y a sus principales protagonistas, destacándose los atletas Ezequiel Kemboi (Kenia), Sandra Richards (EE.UU.) y Usain Bolt (Jamaica) -todos ellos retratados por él,

4 Pictures of the Year es un concurso anual en el que participan fotógrafos de documentales y reporteros gráficos. Pertenece al programa dedesarrollo profesional paraperiodistas visuales, Pictures of the Year International. 
segundos después de ganar la medalla de oro- haciendo uso de su iPhone 4S, un lente Schneider y binoculares Canon. Al respecto, el diario The Guardian (2012), en su plataforma digital indicó « 2012 ha sido el año en que los teléfonos inteligentes han comenzado a dominar el mundo de la fotografía fija. Siga al periodista gráfico de Guardian, Dan Chung, mientras captura los Juegos Olímpicos de Londres 2012 utilizando teléfonos inteligentes» (párr. 1).

A finales de aquel año la revista Time tuvo como portada una fotografía captada con un Smartphone. La imagen, cuyo autor es el fotoperiodista Benjamin Lowy, muestra el desastre meteorológico que azotó Estados Unidos en aquella época. Por obvias razones la imagen, que nos muestra una impresionante ola inmersa en el embravecido mar en el instante mismo de la 'tormenta perfecta', no es de una excelente calidad.

Sin embargo, cabe destacar que aquella fotografía nos hace apreciar que un Smartphone es un valioso instrumento y aporte para nuestra profesión si un fotoperiodista tiene el suficiente criterio periodístico para plasmar en una imagen lo importante del instante y lo que aquel hecho transmite al mundo. Tal fue el impacto del acontecimiento, que dos años después la editorial Daylight (2014) publicó \#Sandy: Seen Through the iPhones of Acclaimed Photographers, en el cual se muestran varias imágenes del huracán captadas con los teléfonos móviles de distinguidos fotoperiodistas, entre ellos Ruddy Roye, Stephen Wilkes y el propio Benjamin Lowy.

En una conversación con la comunidad fotográfica de EyeEm (2013) respecto a su experiencia usando el Smartphone en el ejercicio de su labor fotoperiodística en Afganistán y Libia, Lowy refiere que ello le resultaba muy cómodo puesto que su teléfono móvil «era anónimo, no era particularmente pesado, no se interponía en la intimidad con un potencial tema. Y fue rápido, podía sacar el teléfono del bolsillo y tomar una fotografía mientras sucedían las cosas frente a mí» (párr. 9).

En el 2013 un suceso que se dio a conocer en tiempo real por medio de un Smartphone fue el atentado ocurrido en la maratón de Boston. Aquella vez los periodistas de The Boston Globe informaron del hecho enviando las primeras fotografías del ataque por medio de sus teléfonos móviles vía Twitter. Posteriormente, el diario fue galardonado con el Premio Pulitzer (2014) en la 
categoría 'Informes de noticias de última hora', por su «exhaustiva y empática cobertura de los atentados en la maratón de Boston y la persecución subsiguiente que envolvió a la ciudad, utilizando la fotografía y una gama de herramientas digitales para capturar el impacto total de la tragedia» (párr. 3).

Al año siguiente, en el 2014, la revista Time premió como 'Fotógrafo de Instagram del año' al fotoperiodista David Guttenfelder, quien se desempeñaba como corresponsal de la agencia Associated Press en Pyongyang. El también ganador hasta en siete ocasiones del World Press Photo, obtuvo esta distinción gracias a sus fotografías con el Smartphone en la capital de Corea del Norte.

Al ser uno de los pocos profesionales que ha logrado conseguir un permiso oficial de aquel gobierno para realizar un trabajo fotoperiodístico, las imágenes que Guttenfelder muestra nos dan a conocer la vida cotidiana de ese país: gente montando bicicleta o en transporte público, niños estudiando en una escuela rural, obreros trabajando en fábricas, paisajes de la ciudad, etc. «Usar un dispositivo pequeño permite tomar imágenes más sensibles porque es mucho más discreto (...) Como siempre llevaba mi iPhone en mano, empecé a retratar muchas cosas nuevas, todo en detalle (...) Me siento responsable de mostrar lo que es este país», sostuvo Guttenfelder en un diálogo con Stevan (2016, párr. 5).

En estos últimos años, más precisamente en el 2017, la revista Time culminó con el proyecto Firsts, el cual consistía en fotografiar a las 46 mujeres estadounidenses más sobresalientes o relevantes del país, tales como Janet Yellen, Serena Williams, Hillary Clinton, Lori Jean Robinson y Sheryl Sandberg, entre otras. El trabajo fue realizado por la fotoperiodista Luisa Dörr, quien hizo uso de su teléfono móvil para retratar a estas mujeres quienes luego aparecerían en la portada de la reconocida publicación.

Las fotografías que se han convertido en el primer portfolio de Time hecho con un Smartphone, fueron iniciadas con un iPhone 5S, pero la mayoría de ellas se realizó y culminó con el iPhone 7plus. Tal como narra Martín (2017), Dörr fue contratada debido a que la editora de fotografía de aquella revista, Kira Pollack, deseaba que las fotografías del proyecto Firsts tuvieran la misma naturalidad de las imágenes que la fotoperiodista brasileña captaba y mostraba en sus redes sociales, lo cual solo se conseguiría fotografiando con un teléfono 
móvil puesto que ante este instrumento tecnológico el personaje reacciona diferente. «Fotografiar con un iPhone no significa que sea más fácil (...) El móvil fue escogido por la estética, pero la idea y la creatividad de cada foto no las piensa el iPhone, las pienso yo» (párr. 9).

Como dato adicional mencionamos el caso del periodista peruano Bruno Ortiz Bisso, del diario El Comercio, quien en una de sus publicaciones para dicho medio indica haber captado fotografías con su Smartphone Huawei P20 PRO para complementar la nota informativa en la que narra cómo observaba el ambiente futbolístico a un mes de iniciarse el mundial de fútbol Rusia 2018. «Con datos, solo con Wi Fi, grabando videos y tomando fotos gran parte del día (tengo en galería más de 1300) (...) Traté de empujar al máximo este Smartphone y la buena noticia es que rindió sin problemas» (Ortiz, 2018, párr. 28).

Tal ha sido el progreso del fotoperiodismo por medio del Smartphone, que desde el 2011 se celebra el Mobile Photography Awards con el que se busca reconocer y celebrar el talento y las imágenes de las comunidades de fotografía móvil. La imagen ganadora en la categoría de fotoperiodismo, en la séptima edición del Mobile Photography Awards (2018), pertenece a Neha Wadekar, quien con su fotografía Election Fury, Nairobi nos da a conocer el contexto de violencia que se vivió en Kenia durante las elecciones presidenciales en las que Uhuru Kenyatta se reeligió con el $98 \%$ de los votos luego de que su opositor Raila Odinga no se presentara alegando falta de credibilidad en el proceso electoral.

Evaluamos así que desde un inicio el Smartphone ha sido un instrumento valioso para la labor del profesional en fotoperiodismo, puesto que es de utilidad para dar cobertura tanto a grandes eventos deportivos y en escenarios tranquilos, como también en contextos de suma dificultad y tensión. Resaltamos, asimismo, que no es necesario contar con un teléfono móvil muy costoso y de alta tecnología para que nuestro trabajo obtenga imágenes de calidad y sea finalmente publicado, sino que ello dependerá de las cualidades técnicas y profesionales del fotoperiodista.

«Con el iPhone 4S, la cámara pasó a ser al menos finalmente aceptable (...) Lo suficientemente buena como para llegar a un libro de la National Geographic», refiere el fotoperiodista Richard Hernández (como se citó en 
Marshall, 2013, párr. 17), en cuyo trabajo, realizado con la colaboración de otros profesionales del rubro: Damon Winter, Michael Christopher Brown y Carsten Peter, y publicado por la prestigiosa revista, nos narra sus experiencias con la cámara del iPhone y las aplicaciones usadas para dicha labor.

\section{Aplicaciones (apps) del Smartphone útiles para el fotoperiodismo}

Debido a que nos encontramos en un continuo avance tecnológico es que también las diversas apps que van apareciendo se hallan en el mismo proceso. Esa es la razón por la que consideramos de suma importancia que el fotoperiodista se encuentre en permanente capacitación para que así pueda utilizar de manera adecuada y sin inconvenientes las apps en su versión más actualizada, y de ese modo ejercer cabalmente su profesión.

Si bien conocemos que los elementos esenciales para la obtención de una buena fotografía son el talento y la capacidad del fotoperiodista, así como una excelente cámara del Smartphone, creemos que también es oportuno que aquel profesional tenga a su disposición las apps que, previo a la realización de su labor, le permitan equilibrar la cantidad de luz, el balance, la distancia de enfoque y otros aspectos, y así lograr captar una mejor imagen.

Por ello es que a continuación revisaremos algunas de estas apps que el fotoperiodista puede emplear para aquel fin, precisando que no haremos mención de ninguna aplicación que pueda usarse posteriormente al ejercicio de su labor, como las destinadas a la edición fotográfica, ya que esto último, como dijimos anteriormente, es manipulación periodística.

Una primera opción es Camera ZOOM FX Premium ya que permite realizar imágenes RAW y seleccionar la velocidad de obturación, la distancia de enfoque, combinar modos de disparo (estable con medidor en pantalla, activado por voz, con temporizador), la exposición y el ISO. Excelente para captura en pantalla ancha 'widescreen', establecer acciones para los botones físicos: botones de volumen para controlar el zoom, trackball para tomar la fotografía, etc.; a la vez que se logra modificar las opciones del dispositivo, como el enfoque automático o el balance de blancos. Además cuenta con zoom óptico/digital (hasta 6 aumentos) y guardado automático de las fotografías. 
También tenemos PhotoPills con la que logramos conocer el momento exacto del día en el que se presentan las mejores condiciones de luz para fotografiar determinados paisajes: los crepúsculos, la hora dorada y la hora azul. Sus visores 3D de realidad aumentada de su calculadora de profundidad de campo permiten apreciar en donde se debe enfocar para obtener una mejor nitidez; además, posee calculadoras para realizar fotografías de larga exposición, los timelapses, medir la profundidad de campo o la hiperfocal en función de la cámara que utilicemos. Tiene también gestor de planificaciones y de localizaciones, así como la opción de almacenar toda la información que se va registrando.

Otra aplicación es Cámara FV 5 con la cual todos los controles se encuentran siempre presentes sin necesidad de ingresar a un menú: modo de enfoque, de programa y de medición de luz, ISO, balance de blancos y compensación de la exposición (EV); además de procesar y grabar las fotos JPEG y RAW en un segundo plano, lo cual genera una sensación de trabajo continuo. Tiene también un visualizador característico de las cámaras DSLR profesionales, en la que se aprecia la apertura del diafragma y el tiempo de exposición. Asimismo, nos permite configurar el modo de enfoque: macro, completamente manual, automático y al infinito, a la vez de contar con un botón para bloqueo de enfoque.

Una herramienta muy útil y recomendada es Hipstamatic gracias a que nos posibilita crear una variedad de fotografías al estilo retro con base en tres filtros (lente, película y flash), los cuales se aplican cuando se dispara la foto y que al usarse de manera combinada nos permite captar fotografías con diversos efectos que van desde antiguos desteñidos hasta en blanco y negro de alto contraste. Con el filtro de lente se determinan los colores y tonos; con el filtro de película se logra el marco o viñeta alrededor del borde de la imagen; y con el filtro de flash se pueden generar distintos efectos de iluminación. Cuenta además con dos modos de cámara o interface: el ClassicMode que imita el aspecto de la cámara analógica, y el ProMode que brinda una apariencia digital para una mejor precisión y control manual.

Podemos emplear también Cameringo + Cámara de Filtros con la que logramos más de 300 filtros fotográficos personalizados: pintura artística, retro, vintage, análogos y otros más, destacando los filtros de mapeo en los que 
aplicamos los tonos FAUX HDR. Tiene además el modo de obturador silencioso y un estabilizador de imagen inteligente que equilibra el movimiento de la cámara para eliminar el desenfoque; así como los controles DSLR profesionales con los que modificamos al instante el contraste o la exposición. De igual manera, conseguimos un mejor ángulo de la foto al utilizar el indicador de nivel de horizonte, a la vez que nos permite contrastar la última foto captada con la imagen en vivo mientras realizamos los disparos fotográficos en el modo de revisión de fotos.

Por otro lado, también tenemos a HyperFocal Pro, con la que se logran configurar los parámetros de disparo y apreciar todo lo vinculado al enfoque en un solo punto, además de conseguir con precisión los diversos cálculos de la fotografía en lo relacionado a la profundidad de campo, el campo de visión o la distancia hiperfocal; incluyendo con ello una avanzada representación gráfica de la escena que será fotografiada. Tiene asimismo diferentes 'perfiles' para la gestión de variadas configuraciones: cambiar de forma rápida los diversos parámetros de disparo, de lente y combinaciones de cámara, así como el guardar nuestras propias tablas de hiperfocales.

Una última aplicación es Open Camera, cuya característica primordial es ser una app de código abierto, lo cual le permite tener actualizaciones permanentes y así estar en mejora constante. Con esta aplicación logramos obtener fotografías perfectamente niveladas gracias a su estabilizador automático, además de ajustar el disparador para captar la fotografía mediante comando de voz, toques en la pantalla o emitiendo un sonido (un silbido, por ejemplo). Asimismo, nos proporciona una interfaz para fotógrafos zurdos, así como el geoetiquetado para añadir coordenadas geográficas a nuestra imagen y de ese modo guardar en el sistema el lugar exacto en la que se realizó. Adicionalmente, podemos configurar el modo de escena (HDR o auto), el balance de blancos (día nublado, fluorescente o luz de día), la compensación o bloqueo de exposición, el ISO, el modo de enfoque (infinito, continuo, automático o bloqueado), el flash y la calidad de resolución de las fotografías.

Destacamos que actualmente las aplicaciones como herramientas tecnológicas son importantes para el profesional en fotoperiodismo que emplea un Smartphone en el desarrollo de su trabajo. Sin embargo, si bien las apps son un buen complemento para el teléfono móvil en aquella labor, debemos 
precisar que la obtención de una buena fotografía periodística solo dependerá del criterio ético y profesional del fotoperiodista; tal como lo explica el ganador del Premio Pulitzer, David Hume Kennerly, en su libro David Hume Kennerly On the iPhone: Secrets and Tips from a Pulitzer Prize-winning Photographer: «Las aplicaciones son herramientas fantásticas y me gusta usarlas. No creo que haya nada de malo en eso (...) No se trata de las aplicaciones sino de tu ojo y de cómo ves el mundo» (como se citó en Weiss, 2015, párr. 10 y 12).

\section{Conclusiones}

El empleo de las apps por medio del Smartphone ha variado la manera en que se desarrolla el fotoperiodismo, facilitando el ejercicio profesional del fotoperiodista, ya sea para captar una mejor imagen, transmitir las fotografías en tiempo real por medio de Internet (y con ello no perderlas) o en el traslado mínimo de equipos.

El actual contexto digital permite que la tecnología se encuentre en constante evolución, por lo que todas las aplicaciones mencionadas en el estudio, así como también los Smartphone referidos, siempre estarán en continua actualización, lo cual debe conllevar a que se promuevan investigaciones referidas a esta temática, y a otras similares, que en este momento aún son escasas.

Por otro lado, si bien algunos estudios pueden indicar que el fotoperiodismo se encuentra en una situación crítica por el uso masivo de los teléfonos móviles con cámara, los fotógrafos profesionales deben poner énfasis en que la relevancia de su labor no se encuentra únicamente en captar la cotidianidad, sino en que sus fotografías transmiten un mensaje con enfoque periodístico al público que las observan.

Es en esa perspectiva que los fotoperiodistas deben capacitarse en el empleo de las NTIC que surgen continuamente, adaptando sus aptitudes profesionales al contexto tecnológico que es la sociedad de la información, para seguir realizando su labor con los mismos principios éticos y de integridad profesional, propios del ejercicio periodístico. 


\section{Referencias}

Altares, G. (2014). ¿Y si Robert Capa solo tomó 11 fotos en el desembarco del Día D? Recuperado de https:/l bit.ly/2KSjRwl

Asociación de la Prensa de Madrid - APM. (2017). Informe anual de la profesión periodística 2017. Recuperado de https://bit.ly/2vsRgbl

Caballo, D. (1994). El editor gráfico de prensa en las agencias con redes mundiales de telefotografía (Tesis doctoral). Recuperada de https://bit.ly/2KJZBNx

Castellanos, U. (2004). Manual de fotoperiodismo: retos y soluciones. México D. F.: Universidad Iberoamericana.

Colegio de Periodistas de Cataluña. (2018). O calidad o nada. Recuperado de https://bit.ly/2L1uOgw

Daylight. (2014). \#Sandy: Seen Through the iPhones of Acclaimed Photographers. Recuperado de https://bit.ly/ 2w8RwfW

DxOMark. (2017). 2017, the year of the new mobile protocol. Recuperado de https://bit.ly/2vVYe9X

Ericsson. (2018). Ericsson Mobility Report. Recuperado de https://bit.ly/2JErBCy

Espejo, B. (diciembre, 2015). Antes la fotografía era escritura. Hoy es lenguaje. Recuperado de https://bit.ly/ 2MpDIF7

EyeEm. (2013). War Through an iPhone Lens. Q\&A with Ben Lowy. Recuperado de https://bit.ly/2vTSH3w

Galdón, G. (2001). Información, desinformación y manipulación. En G. Galdón (Ed.), Introducción a la comunicación y a la información (pp. 47-75). Barcelona: Ariel.

Groupe Speciale Mobile Association - GSMA. (2018). The Mobile Economy 2018. Recuperado de https://bit.ly/ $2 \mathrm{rJkfcb}$

Marshall, T. (2013). Photojournalists Move To Instagram, From Syria to Sandy. Recuperado de https://bit.ly/2LrOTf4

Martín, M. (septiembre, 2017). La fotógrafa brasileña que llevó un iPhone a la portada de 'Time'. Recuperado de https://bit.ly/2vWMkN4

Martins, A. (enero, 2006). «iDios mío, no quiero que muera!». Recuperado de https://bbc.in/2OvBnc3

Mc Bride, S. (1980). Un solo mundo, voces múltiples. Comunicación e información en nuestro tiempo. México D. F.: Fondo de Cultura Económica.

Mobile Photography Awards. (2018). Photo Journalism. Winner \& Honorable Mentions. $7^{\text {th }}$ Annual MPA. Recuperado de https://bit.ly/2P6FHit

Monje, M. (agosto, 2017). El rol social de la fotografía en la era de las redes sociales. Recuperado de https:/l bit.ly/2B6wxjX

Ortiz, B. (2018). Smartphones: Evaluamos el Huawei P20 Pro. Recuperado de https://bit.ly/2MTifHM

Premio Pulitzer. (2014). 2014 Pulitzer Prizes. Recuperado de https://bit.ly/2PFiGUW

Sanmoran, C. (noviembre, 2017). No basta con llegar primero a un sitio, hay que desarrollar un discurso visual. Recuperado de https://bit.ly/2vDAW8B

Schaeffer, J. M. (1990). La imagen precaria del dispositivo fotográfico. Madrid: Ediciones Cátedra.

Stevan, C. (setiembre, 2016). Instagram a changé ma vie de photographe. Recuperado de https://bit.ly/2MxH70z

Telefónica. (2017). Sociedad Digital en España 2017. Recuperado de https://bit.ly/2ofzPaA

The Guardian. (2012). Fotoblog de Olimpiada Olímpica de Dan Chung. Recuperado de https://bit.ly/2MbucWg

Weiss, J. (2015). Ganador del Pulitzer te explica cómo tomar una foto perfecta con tu iPhone. Recuperado de https://bit.ly/15B1Vld

Winter, D. (2011). Through My Eye, Not Hipstamatic's. Recuperado de https://nyti.ms/2Bs4BXM

World Press Photo. (2016). The state of news photography 2016. Recuperado de https://bit.ly/2vE1QgJ 